\title{
Integrating risk management in the innovation project
}

\section{Integrating risk management}

\author{
John Bowers \\ University of Stirling, Stirling, UK, and \\ Alireza Khorakian \\ Ferdowsi University of Mashhad (FUM), Mashhad, Iran
}

\begin{abstract}
Purpose - While innovation has many similarities to other forms of projects it is characterised by a high failure rate and the need to stimulate creativity. More explicit risk management could help in achieving success in innovation projects. However, too much or inappropriate risk management might stifle the creativity that is core to innovation. So, what project risk management should be applied and where in the innovation project?

Design/methodology/approach - A theoretical framework is proposed which combines the generic innovation process with project risk management. The framework was used to analyse the current attitudes to managing innovation risk in a series of companies.

Findings - The decision points of the stage-gate innovation process model provide an effective interface for incorporating project risk concepts. The general concepts appear most relevant to innovation management though it is useful to customise them to emphasise the particular characteristics of innovation projects. The experience of using the resultant combined model in a number of diverse case studies indicates the relevance of the model in understanding attitudes towards risk management in innovation. The analysis of the case study companies suggested that risk management needs to be applied in differential manner: simple, unobtrusive techniques early in the innovation life cycle with more substantial, quantitative methods being considered for later stages.

Research limitations/implications - It would be useful to extend this research by examining more case studies from other countries and industries.

Practical implications - The combined innovation and risk management model provides a framework that diverse companies can appreciate. The framework offers a basis for discussing the most appropriate form of risk management in different innovation-based industries.

Originality/value - Although there are many separate models for innovation and project risk management described in the literature, there is very little discussion about explicitly combining these theories. This paper aims to help fill this gap in the knowledge.
\end{abstract}

Keywords Management, Innovation, Risk, Integration, Project

Paper type Research paper

\section{Introduction}

Companies have to innovate in order to survive (Taplin and Schymyck, 2005) and in economic recessions innovation can help convert a crisis into an opportunity (Mahroum, 2008; Lazzaron, 2010). However, in such turbulent times add further risk to that inherent in innovation (Zhao, 2005; Wang et al., 2010) and product innovation is recognised as an especially high-risk business activity (Stevens and Burley, 1997). Greater competition, rapidly changing technology and customer expectations tend to make innovation more complex with less predictable outcomes (Keizer et al., 2005), increasing the innovator's exposure to risk (Berglund, 2007). While companies should not pursue a strategy of risk avoidance, better project risk diagnosis and management might help adjust the balance between success and failure. More extensive use of explicit risk management might reduce expenditure on failed innovations and also accelerate projects (Mu et al., 2009; Johnson, 2010). But too much or inappropriate risk management could discourage and

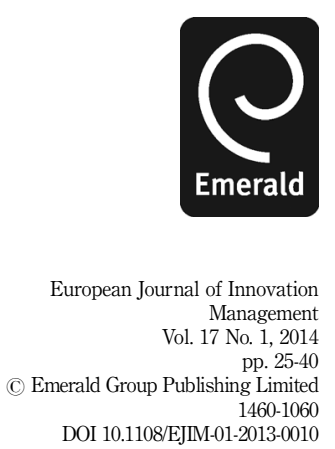


EJIM

17,1

\section{6}

stifle innovation (Taplin and Schymyck, 2005): a balance is needed. Many organisations recognise the need for a risk management system integrated within project management in general (Williams, 1995; Emblemsvåg and Kjølstad, 2006) but this practice is rarely explicit in innovation management.

The main objective of this paper is to consider whether the concepts of project risk management have a role in innovation. The paper explores inter-relationships between models of innovation and project risk management, developing an integrated framework. The framework is then used to examine attitudes to innovation project risk management through a series of five case studies. The studies involved interviews with a range of staff in each company reflecting the roles of different management functions in the innovation process. The experience suggests that the combined framework is relevant in diverse industries and may help to bridge the gap between project risk and innovation management. The paper also offers some more specific recommendations: comprehensive, rigorous risk management can be appropriate at some stages, in some innovation projects, but simpler risk management tools may often be more effective.

\section{The need for risk management in innovation}

Innovation is the use of newly acquired knowledge in developing a new product or service (Afuah, 2003). Novelty is central to innovation but this inevitably implies risk. Risk is found in all projects but it is especially important in innovation and a high failure rate is common (Simon, 2009): 35 per cent of innovation projects fail commercially, accounting for 45 per cent of new product expenditure (Halman and Keizer, 1994). In some industrialised countries the success rate of new products is 15 per cent and among developing countries, such as Hong Kong, it is just 2 per cent (Ozer, 2006). Efficient innovation management should identify the unacceptable risks as early as possible but often they only become apparent in the later stages, at great expense. However, a fear of failure would be detrimental to innovation; indeed accepting the possibility of failure as an everyday reality is one of the defining characteristics of the innovation project. Any model of the innovation process needs to incorporate failure as a likely outcome. In many other projects abandoning the venture is a theoretical but remote option whereas in the innovation project it is integral to good management. Risk management can help managers make the critical decision to abandon a project, providing an effective filter of the good and poor prospects and helping direct the continuing research that is fundamental in innovation projects. Risk is central to innovation but it is often not managed explicitly. This is in contrast to some other areas of project management where risk has become a major theme (e.g. see: Smith and Merritt, 2002; Smith et al., 2006; Aloini et al., 2007; Lam et al., 2007).

Creativity is a distinctive characteristic of the innovation project and this stage is often problematic (Dewett, 2004; Burroughs et al., 2011). It can be difficult to encourage people to generate ideas and excessive risk management might deter radical suggestions stifling this critical stage. When determining the appropriate, cost-effective form of risk management, all projects have to consider the costs, data availability and the management value of the outputs of the additional analyses. Innovation projects also have to balance the possible effect on creativity. Risk management is implicit throughout the innovation process but there may be value in making it more explicit by integrating the models of innovation and project risk management.

\section{Innovation process models}

There are many models of the innovation process capturing the various stages from the generation of the new ideas through to full scale implementation (e.g. see: Goffin 
and Pfeiffer, 1999; Narvekar and Jain, 2006; Chandra and Neelankavil, 2008). These models were typically developed to manage the innovation of new manufactured products but the same concepts are relevant in process and service innovation (Gobeli and Brown, 1993). The use of more formal management processes has helped improve innovation performance in a range of industries (Griffin, 1997; Tatikonda and Rosenthal, 2000). These formal processes distinguish the classic aspects of innovation management: creativity and ideas management; selection and portfolio management; implementation (Oke, 2007). Many companies adopt a stage-gate approach, considering the process as a series of stages with intermediate decision points. This provides an operational structure taking new products from idea to launch and beyond (Cooper, 2008). However, one criticism of the stage-gate approach is that it focuses on process factors potentially ignoring organisational factors that can have a major impact on innovation performance. The Pentathlon framework (Goffin and Pfeiffer, 1999) offers a more general model including a wider range of soft organisational issues.

Although there are many variations, the same basic process model can often be identified (Tidd et al., 2005) as in the standard five stage model adopted for this study: creativity, selection, incubation, implementation and learning. The first critical stage of creativity involves examining the internal and external environment: customers' needs, competitors' products and in-house R\&D can all be sources of creativity. Selection follows as the company assesses the relative merits of competing ideas, considering the organisation's strategy and operational constraints. In the incubation stage the company develops a prototype, using it to identify problems and resolving them before progressing to the larger scale activity of the following stages. During implementation the company scales up the prototype to full production and launches the product in the market. Whether the innovation is successful or not, the experience should provide an opportunity to learn, with the company expanding its knowledge base to support future innovation (Tidd et al., 2005). Given the high failure rate in innovation, this ability to manage knowledge is most important. Many innovations projects fail but they may still make a valuable contribution, helping develop the expertise that leads to future success (Worthington et al., 2009).

\section{Integrating project risk and innovation management models}

Each of the stages of the innovation process can be viewed as an information gathering activity. This may involve a variety of specific actions including trials of prototypes, laboratory safety tests, computer modelling, market research, investigations of potential raw materials and assessment of skills' availability. The information is reviewed at the subsequent decision point considering appropriate criteria. The specific criteria may vary between organisations reflecting the local context but will be consistent with those generally judged to be critical to success in product innovation (Keizer et al., 2002). Each decision involves determining the prospects for the innovation and the merits of progressing to the next stage, or abandoning the project. This cycle of information gathering, analysis and management action is itself a form of risk management. However, project risk management makes this process more explicit, formalising the information collection and analysis while acknowledging that many of the data are uncertain. The risk analysis involves estimating the probability of the innovation achieving the desired objectives and also identifying the remaining uncertainties that need to be addressed in the subsequent stages of the innovation process. Figure 1 illustrates this model combining the concepts of the stage-gate innovation process with project risk management. Such graphical models can help
Integrating risk management

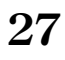




\section{EJIM}

17,1

28

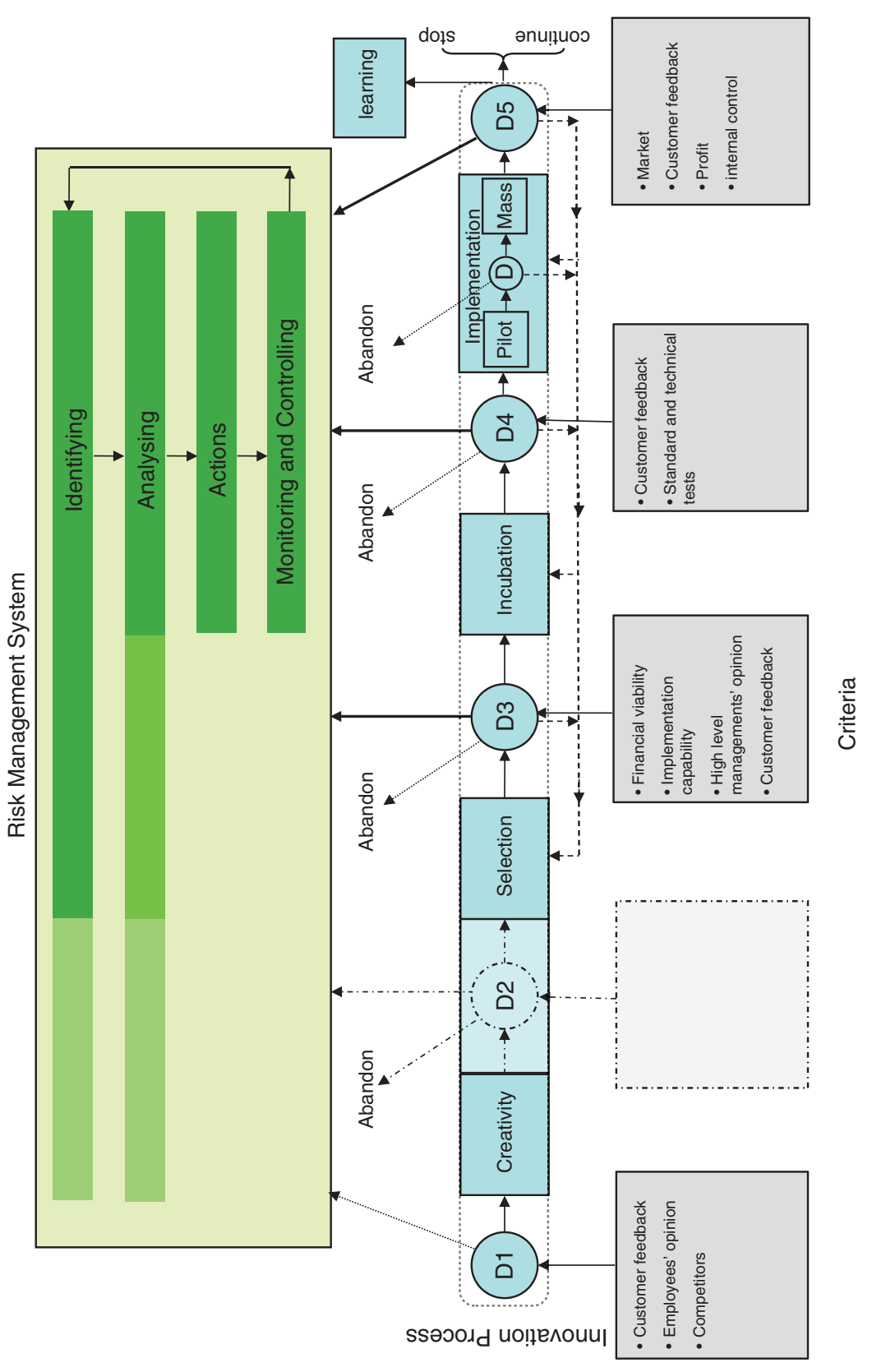

Figure 1.

A framework combining risk and innovation management 
communicate practice and stimulate debate (Smith and Merritt, 2002). While decisions may result in abandoning innovation projects that are assessed to be high risk, the outcomes do not always have to be a binary "progress" or "abandon". Sometimes the outcome may be a recommendation that the decision to proceed is postponed until additional data are provided resulting in a more iterative innovation cycle rather than a simple linear progression, as noted in some variations of the standard stage-gate model (Cooper, 1994). Project risk management encompasses a wide range of technical, financial and market risks and also a range of potentially critical soft organisational issues, as recognised in the Pentathlon model (Goffin and Pfeiffer, 1999; Oke 2007).

Risk analysis techniques are often classified as qualitative or quantitative (Table I). In many projects the management requirement is to understand the relative severity of the risk, compared to other projects and options available to the organisation. Qualitative risk analysis is often sufficient and the quality of the data do not justify any more sophisticated techniques (Patterson and Neailey, 2002; Edwards and Bowen, 2005). Quantitative techniques offer more rigour and objectivity but they are very demanding in terms of data. They typically involve a statistical analysis of historic data drawn from a database of experience developed in previous projects. Quantitative analysis is expensive and requires considerable expert effort but this may be justified in large-scale projects, providing a disciplined and relatively objective risk assessment. However, quantitative data are not always objective and care is needed, as noted in Table I. For example, Monte Carlo simulation is a classic quantitative technique but the estimates of the uncertainties may be obtained from a diverse collection of sources, including expert judgement implying a degree of subjectivity (Bowers, 1994). Although a variety of sources may be used, blending different types of data to provide the input for the quantitative models, the available quantitative data may still be limited. If quantitative analysis is deemed essential, data availability may restrict the scope and critical risks may be ignored (Ahmed et al., 2007). In contrast, qualitative analysis tends to be cheap, flexible and quick to apply. However, it usually relies on human judgement, with the inevitable scope for personal bias, experience and preference (Edwards and Bowen, 2005; Patterson and Neailey, 2002). The bias can be minimised using systematic techniques such as risk mapping to enhance the transparency of the analysis. Techniques such as event tree analysis (ETA), fault tree analysis (FTA), failure modes and effect analysis (FMEA) maybe used in either a qualitative manner or incorporating quantitative data if desired.

\section{Customising project risk concepts}

Project risk management has evolved in a range of industries and a set of general concepts has been developed (e.g. see: Smith and Merritt, 2002; Smith et al., 2006; Aloini et al., 2007; Lam et al., 2007). Although the detailed implementation has to be customised to suit the particular context, the core risk management activities can be summarised as identification, analysis, action, and monitoring and controlling risk, as incorporated in the framework of Figure 1.

\begin{tabular}{lll}
\hline Subjective Objective \\
\hline
\end{tabular}

Quantitative (such as Methods of moment, Monte Carlo simulation and

Exact algebraic solution)

Qualitative (such as Risk mapping, ETA, FTA, FMEA)
Integrating risk management

29

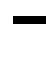

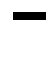


EJIM

17,1

30

In the identification phase, a project's specific potential sources of risk are distinguished. A wide range of factors can create risk in innovation and a variety of categorisation schemes have been proposed that can help structure the risk identification activity (e.g. see: Eden, 2001; Keizer et al., 2002; Berglund, 2007). Using these schemes and also experience from innovation case studies (e.g. see: van de Ven et al., 1999), this study adopted a high-level categorisation of possible risk factors for innovation projects: environment, technical, resources, management, marketing, integration and strategy. Each of these categories include sub-divisions, for example, "environment" includes: governmental policy (Foxon et al., 2005), currency rates (Eden, 2001), weather (Green and Serbein, 1983), intellectual property (Keizer et al., 2005), as well as social factors such as poverty, crime and culture (Green and Serbein, 1983). The consequences of each potential source of uncertainty may be positive or negative, for example, a change in government policy relaxing regulations could increase the profitability of a product but it may also encourage other companies to enter the market.

Various risk identification techniques may be used, including checklists, cause and effect analyses, influence diagrams, and hazard and operability studies (e.g. see: Chapman and Ward, 1997; Ahmed et al., 2007). Structured checklists, using a hierarchy reflecting a risk categorisation scheme, can support simple, quick and effective risk identification. Risk checklists should be dynamic, evolving over time through contributions from various functional experts and collective experiences (Chapman and Ward, 1997; Ward, 1999). A risk checklist can be a practical mechanism in for organisational learning, disseminating knowledge from previous innovation projects across the company (European Federation of Chemical Engineering, 1985). The checklist should include company specific, as well as generic success factors and encourage project team members to consider the less obvious issues and possible new sources of risk (Keizer et al., 2002; Edwards and Bowen, 2005; Ackermann et al., 2007). Following the initial risk identification, the risk checklist provides the basis of the risk register recording regular reviews of a project's risk and the management responses in a dynamic process (Williams, 1994; Patterson and Neailey, 2002). This dynamic approach can be especially important in innovation projects where there is a high degree of novelty: lessons may be learned from previous projects but it is always to be aware of new sources of risk.

Having identified a project's potential risks, a more detailed analysis may follow typically based on two parameters: probability and impact (e.g. see: Chapman and Ward, 1997; Zhao, 2005). Simpler, qualitative risk analysis (Patterson and Neailey, 2002) may be sufficient in the early stages of innovation projects since the main requirement of the earlier stage-gate decisions is for an understanding of the relative severity of the risks rather than a precise estimate of the absolute risk (Edwards and Bowen, 2005). Quantitative risk analysis typically requires a substantial statistical analysis of relevant historical data. However, such data may not be readily available and the environmental or technological change inherent in many innovation projects may make some of the older data irrelevant.

Risk analysis is followed by management action. A suitable response for each risk should be specified and recorded in a risk register. Many generic project risk management actions have been identified and these may be summarised in categories reflecting the particular characteristics of innovation projects (e.g. see: Pyra and Trask, 2002; Smith and Merritt, 2002):

- acceptance: the company decides to do nothing about the risk, accepts the risk and its consequences; 
- avoidance: revising the project plan to remove the risk; in innovation this may often involve recognising the increased likelihood of failure and abandoning the project;

- transfer: risk responsibilities may be reallocated in a more appropriate manner; a company may realise that it does not have enough experience with a vital technology and decide to sub-contract part of the development, or even sell the partially developed product to another organisation;

- redundancy: in some cases, such as new drug developments, the high failure rate of innovation leads to the use of parallel paths to increase the probability that an effective solution will emerge; and

- mitigation: reducing uncertainty or the impact is fundamental to managing project risk management and many of the routine activities of innovation might be described as mitigating risk, undertaking more technical or market research, performing laboratory tests, developing prototype products and building small scale pilot production plants can reduce the probability or impact of risk.

Having agreed the appropriate management actions, their effects should be subject to continuous monitoring and controlling. While there is variation in the approaches (e.g. see: Turner, 1993; Smith and Merritt, 2002) all emphasise the need to regularly review the status and closure of targeted risks and to identify new risks, typically using a formal risk register. This process is reflected in the decisions of the framework of Figure 1, with each decision implying a review of the risks highlighted in the previous stages.

Many project success factors have been identified as being potentially important in innovation (Cooper and Kleinschmidt, 2007; Simon, 2009) and these provide a basis for selecting the decision criteria of Figure 1. Although risk management should use this generic knowledge, it must also consider the specific context of the particular innovation project (Keizer et al., 2002). Some companies adopt a formal approval mechanism using such decision criteria to determine whether a project may proceed to the next stage of innovation, other companies use more informal approaches.

\section{Methods}

The main objective of this study was to determine whether project risk management can offer an explicit contribution to the innovation process. The first explanatory phase involved exploring the literature form the two management disciplines led to the development of the combined framework. This framework appears to provide a consistent model to help appreciate the inter-relationships between project risk and innovation management theory. The second phase of the study used this idealised model in an exploratory manner. It provided a clear structure for examining practice and then identifying the potential for enhanced risk management in innovation. As in other studies, the case study strategy contributes to both theory-testing and theorybuilding (Eisenhardt and Graebner, 2007).

The combined model of Figure 1 was used to examine innovation risk management with 40 interviews across five case study companies from Iran and the UK, see Table II. As Table II shows the average age of the companies was more than ten years; mature companies were selected since they have had the opportunity to develop risk management skills and experience (Mu et al., 2009). The nature of the risk management can be related to the company size (Mu et al., 2009) so the companies chosen were all relatively large. Furthermore all of the case study companies selected had a significant degree of innovation experience. While the companies had some similarity in age, 
EJIM

17,1

Name of company Nature of business Example of innovation ${ }^{\mathrm{a}}$

Number of Location

1. Shahab Khodro Bus manufacturing Converting from diesel to gas

interviewees (year formed)

2. Firoozeh Tile

Tile manufacturing

Unifying the formula of floor

10

Iran (1982)

and wall tiles

32

3. Razavi Dairy

Dairy product

New milk flavours

8

Iran (1994)

Products

manufacturing

Corporation

4. Sepideh Jam Toos

Porcelain manufacturing

5. Scottish and

Production and

Southern Energy supply of energy

New variety of raw materials to reduce the breakage rate

Using waste products as fuel
$7 \quad \operatorname{Iran}(1993)$

$7 \quad \operatorname{Iran}(1993)$

$8 \quad$ UK (1998)

Table II.

The case study companies Note: ${ }^{\text {aS }}$ Some of these developments have since been approved and are now being implemented

experience and size, they operated in diverse industries. Despite this diversity, all of the companies recognised the same fundamental innovation stages though this was not always reflected in their formal management systems and different terms were often used to describe various analyses and management actions.

It was expected that many of the individual interviewees might be unfamiliar with some of the concepts and terms of innovation and risk management so semi-structured interviews were used to collect that data. In the selection of the interviewees, a range of perspectives were sought, spanning a variety of management and technical functions from: financial, production, operation, quality assurance, technical, marketing and sales, business development, research and development. This provided a more complete view of the innovation process in each company and also a degree of validation through the comparisons of the different, independent interviews in each company. The majority of interviewees had more than five years experience; some had worked on specific innovation projects while others had a broader knowledge. Most had at least an undergraduate degree in wide range of subjects from engineering to business and finance. The interviews were summarised using content analysis to help develop the transcripts into a series of five case studies which were then compared to theory, structured using the integrated risk-innovation model.

\section{Current innovation risk management practice}

7.1 Response to the integrated model

A variety of attitudes towards managing innovation risk was identified. However, the combined model appears to be relevant across diverse industries. Staff from different countries (the UK and Iran), industries and functional backgrounds could all relate to it and the framework provided a useful structure in understanding the detail of implementing risk management. The staff discussed examples of innovation in their companies in terms of the five stages of Figure 1. In general there was a clear correspondence between practice and the stage-gate innovation process model. However, there were some deviations, notably the absence of a distinct creativity stage. For instance, the manager of quality assurance in case 1 explained that: "Creativity and selection are part of a single stage because sometimes there are not many different ideas. We do not have many choices, because most of the time, our ideas are based on customers' needs". In some companies at least, there was a paucity of competing new ideas and there was no need for a distinct selection stage. 


\subsection{Familiarity with risk management}

Many of the interviewees (e.g. case 2, Tile Co; case 4, Porcelain Co) were keen to talk in terms of the probabilities of events and reducing the impact of risk suggesting a greater familiarity with the basic concepts of risk management than might be expected in such companies in Iran; the UK interviewees had a substantially greater knowledge. While the companies undertook various actions that are consistent with good risk management, these actions typically involved resolving specific technical problems rather than considering project risk management in a systematic manner. Although some of the Iranian interviewees demonstrated a basic appreciation of more sophisticated risk analysis tools, there was no evidence of significant application. In most companies there was no use of formal, scientific methods in analysing and prioritising risk, even though many interviewees appreciated the potential for such approaches. It was suggested that the attitude to risk management is largely dependent on the attitudes of high-level management (e.g. case 2, Tile Co): some of the managers were thought to be risk averse and less innovative. Interviewees in case 3 (Dairy Co) believe that most managers in state controlled companies in Iran are particularly risk averse when compared with private companies.

\subsection{The potential contribution of more explicit risk management}

The interviewees from all of the companies agreed that innovation always entails risk, and some recognised a need to manage risk more explicitly. For example, a marketing manager in case 3 (Dairy $\mathrm{Co}$ ) cited a new caramel dessert that was developed and launched without any risk analysis: he felt that even a simple analysis might have prompted more incisive questions about the target market and avoided a costly mistake. Although very few of the interviewees had any formal training in project risk management they appreciated that it should be seen as a continuous process throughout the project's life. However, a number of interviewees (e.g. case 2, Tile Co; case 5, SSE) expressed concern that too stringent control of risk in the creativity stage could deter successful innovation, as noted in other studies (Dewett, 2004). For instance, operation manager in case 2 explained that: "One idea developed by this company involved the combination of tile and nanotechnology to produce ceramics which are anti-fungal and anti-bacterial. However this idea was very radical and there was great concern about the risk". The idea was so radical that there was no information about the possible market at the creativity and selection stages; it was impossible to compare the costs and possible income in a quantitative manner. Insisting upon a quantitative risk analysis at this point in the innovation process would have prevented the idea from being developed any further and a valuable product could have been abandoned. The interviewees generally believed that while risk management is appropriate in the later stages, participants need to be encouraged to champion ideas in creativity stage. The interviewees believed that risk management's greatest potential contribution is in the later stages of the innovation process, where the transition to the actual product development and engineering of a particular product or product range takes place; this view has been noted in other studies (Keizer et al., 2002). Interviewees suggested that project risk management should be implemented in a differential manner through the innovation project cycle. Simple risk identification and qualitative analysis may be more appropriate in the creativity stage, avoiding an environment that might discourage novel ideas. In the selection stage the company might begin to move to more formal risk management, analysing and prioritising the risk factors. Ideally, risk analysis should be used not just
Integrating risk management

33 
EJIM

17,1

34 in judging whether the innovation might proceed to the next stage but it should also contribute to specifying the plan for the following stages in the innovation development. The risk analysis should help identify critical gaps in current knowledge, and determine the requirements for more technical and market research. In the later stages of the innovation process there may be opportunity for more quantitative forms of risk analysis and also a greater need for more rigorous risk action plans and monitoring/ controlling of risk. Figure 1 reflects this differential application of risk management with the shading suggesting a lighter touch early in the process. In addition the broken line in this figure, connecting D1 to the risk management system, indicates the need for simple risk identification in this stage (in comparison with other decision points). However, there is no uniform pattern: some staff, an operation manager in case 2 (Tile $\mathrm{Co}$ ) believe that financial risks should be addressed early in the process.

A single approach to risk management is not appropriate for all companies. Some (e.g. case 5, SSE) use a range of techniques but these were adapted to suit the particular innovation project. The characteristics of the industry were also thought to be important. In some industries in Iran the lack of any real competition has a strong influence on the perceived need for more formal methods of risk and innovation management. For instance, the bus and truck manufacturing industry (case 1) is protected from foreign competition and there is little market risk.

\subsection{Risk management and organisational learning}

Acquiring external knowledge, learning from experience and sharing knowledge throughout the company is claimed to be essential in innovation (e.g. see: Jantunen, 2005). However, formal learning seems to have a low priority in the companies examined. The management focus appears to be on the individual innovation projects. Often each project had a distinct budget with few resources available for more holistic activities such as organisational learning. Knowledge of past innovation projects tended to be dependent on individuals' experiences with no formal method of capturing previous experience. This lack of systematically recorded historic data limits the possibility of using more sophisticated forms of risk analysis. Reliable, rigorous risk analysis is impossible when it depends on individuals' availabilities and their memories. Although quantitative historic data can be useful, qualitative data describing past innovations could still be valuable. Although there was general agreement that organisational learning, including formal documentation, was important, this was not reflected in practice. This failure to capture and exploit experience suggests an avoidable knowledge deficit and hence greater uncertainty and risk.

\section{The potential for enhancing risk management practice in innovation projects}

Comparing the combined risk and innovation management model of Figure 1 with the experiences from the empirical cases study suggests some potential for enhancing practice. The companies used a variety of risk analysis and management techniques, even though they may not always have described them as "risk management". However, these techniques were not deployed in a systematic manner. Using the combined model the staff readily discussed gaps in their current management systems and how they might be resolved. Such discussions emphasised the need to deploy risk management with care. In particular innovation is dependent on creativity and there were fears that this could be discouraged by excessive risk management at an early stage. However, simple qualitative risk analysis and management could be valuable as 
part of the process of filtering the innovations, rejecting more bad ideas while retaining the good. More stringent risk management may be more useful in the later stages as the costs and commitment start to increase.

Comprehensive risk management might be deployed at every stage of the innovation project. However, a more selective use could be more appropriate with varying degrees of risk management being employed throughout the innovation process, as suggested by the shading in Figure 1. The issue of nature and timing of the most appropriate risk management is a major question in practice for all projects. Effective risk management should start at the very beginning of the project, and also go well beyond the technical phases to capture lessons for future projects (Smith, 1999). It is commonly claimed that the cost of change and iterations in the design stage is much less than resolving problems in the implementation phase (Salomone, 1995); early identification of risks allied with action to avoid the risk events actually occurring is usually much more preferable than dealing with the outcome (Ahmed et al., 2007). However, it may not be practical or desirable to apply a comprehensive, rigorous risk management system throughout all projects: different aspects of the risk management system may be more useful at different stages of the innovation project.

A distinctive characteristic of the innovation project is the high failure rate. Typically there will be a large number of innovation projects that start at the creativity stage but the large majority will be abandoned at various stages of the innovation process, with very few surviving through to implementation, as illustrated in Figure 2. As an innovation project advances from the creativity stage through to implementation, knowledge increases. There is always a significant degree of uncertainty but if the innovation has been managed well, any project progressing to the later stages should have a good chance of success, as illustrated in Figure 2. The ideal risk management system provides a structure that copes with the high amount of uncertainty inherent in the innovation project and the flows of information from completing studies of technological feasibility, competitor behaviour, regulatory and market demand. The alternative is to rely on a chain of "best guesses" (Tidd et al., 2005).

The costs of abandoning innovation projects vary with the different stages, reflecting the typical investment profile (Salomone, 1995). The creativity stage usually involves minimal investment whereas implementation is expensive. A key objective of the innovation process is to reject the likely failures at an early stage and minimise the

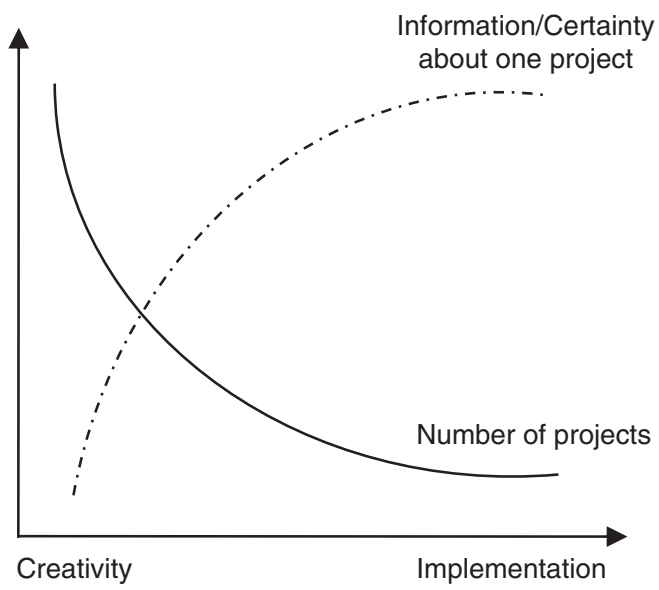

Integrating risk management

35

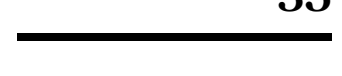


EJIM

17,1

36 implementation of inappropriate products. While companies want to maximise the rejection of potential failures, this can involve rejecting potentially successful prospects (van Oorschot et al., 2010). Figure 3 illustrates four different zones which summarise the relationship between the rejection of good and bad ideas.

If the management is very relaxed, as in zone ${ }^{2}$, there is no effective filter and very few ideas, good or bad, are rejected resulting in high costs as more inappropriate products are pursued through to implementation. In a very critical environment, as in zone III, many good and bad ideas may be rejected. Zone IV is the worst as it rejects all good ideas; zone II represents the most desirable innovation management system with an effective filter, perhaps provided by appropriate risk management. However, achieving such a system is challenging: companies may be tempted into applying stringent risk management in order to move away from zone I only to find themselves operating in zone III, stifling the creativity that is critical to innovation. While it may be impossible to quantify the parameters of Figure 3, the concept was useful when discussing the appropriate balance of risk management.

The combined framework of Figure 1 proved useful as a visualisation tool, facilitating discussion about the appropriate form and timing of risk management at different stages of the innovation project. Each company should customise a risk management system that suits their particular environment. Even a relatively simple but formal template, using structured checklists to help analyse the risk based on past qualitative experience, could offer a significant advance in risk management in many of the Iranian companies. The combined risk and innovation management model may also provide a framework for better collaboration between different organisations. Innovation often involves cooperation at different stages, both between companies and also research institutes. The risk-innovation model can help identify responsibilities, clarifying their relationships.

\section{Conclusion}

Innovation projects are distinguished by the high rate of failure and the need to encourage creativity: a dramatic attrition is expected with a large number of ideas resulting in just a few successful products. The possibility of abandoning a project is ever present and inherent in the management of the innovation process. Risk is a major feature in innovation projects but the focus is resolving technical problems rather than
Figure 3.

The challenges of filtering the good from the bad

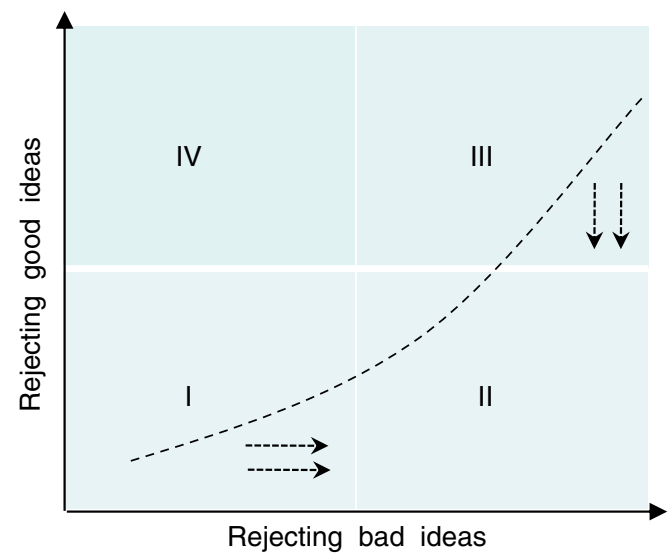


considering project risk management in a systematic manner. There appears to be significant scope for more use of project risk analysis and management, with a greater emphasis on learning from previous projects. However, risk management has to be deployed selectively. In particular there is concern that excessive risk management in the early stages could stifle the creativity that is critical to innovation. The combined innovation and risk management model provided a framework that diverse companies can appreciate. It offers a practical basis for designing the most appropriate form of risk management in different innovation-based industries and it also highlights the possibilities for better integration of the theories of innovation and project risk management. In particular the decision points of the stage-gate model provide an effective interface for incorporating project risk concepts. The general concepts appear most relevant to innovation management though it is useful to customise them to emphasise the particular characteristics of innovation projects.

\section{References}

Ackermann, F., Eden, C., Williams, T. and Howick, S. (2007), "Systematic risk assessment: case study", Journal of the Operation Research Society, Vol. 58 No. 1, pp. 39-51.

Afuah, A. (2003), Innovation Management: Strategies, Implementation, and Profits, 2nd ed., Oxford University Press, New York, NY.

Ahmed, A., Kayis, B. and Amornsawadwatana, S. (2007), "A review of techniques for risk management in projects", Benchmarking: An International Journal, Vol. 14 No. 1, pp. 22-36.

Aloini, D., Dulmin, R. and Mininno, V. (2007), "Risk management in ERP project introduction: review of the literature", Information \& Management, Vol. 44 No. 6, pp. 547-567.

Berglund, H. (2007), "Risk conception and risk management in corporate innovation: lessons from two Swedish cases", International Journal of Innovation Management, Vol. 11 No. 4, pp. 497-513.

Bowers, J.A. (1994), "Data for project risk analysis", International Journal of Project Management, Vol. 12 No. 1, pp. 9-15.

Burroughs, J.E., Dahl, D.W., Moreau, C.P., Chattopadhyay, A. and Gorn, G.J. (2011), "Facilitating and rewarding creativity during new product development", Journal of Marketing, Vol. 75 No. 4, pp. 53-67.

Chandra, M. and Neelankavil, J.P. (2008), "Product development and innovation for developing countries”, Journal of Management Development, Vol. 27 No. 10, pp. 1017-1025.

Chapman, C. and Ward, S.C. (1997), Project Risk Management-Process, Techniques and Insights, Wiley, Chichester.

Cooper, R.G. (1994), "Perspective third-generation new product processes", Journal of Product Innovation Management, Vol. 11 No. 1, pp. 3-14.

Cooper, R.G. (2008), "Perspective: the stage-gate idea-to-launch process-update, what's new, and nexGen systems”, Journal of Product Innovation Management, Vol. 25 No. 3, pp. 213-232.

Cooper, R.G. and Kleinschmidt, E.J. (2007), "Winning businesses in product development: the critical success factors", Research Technology Management, Vol. 50 No. 3, pp. 52-66.

Dewett, T. (2004), "Employee creativity and the role of risk", European Journal of Innovation Management, Vol. 7 No. 4, pp. 257-266.

Eden, C. (2001), "Coping with strategic risk", in Crainer, S. and Dearlove, D. (Eds), Financial Times Handbook of Management, FT/Prentice Hall, London, pp. 285-292.

Edwards, P.J. and Bowen, P.A. (2005), Risk Management in Project Organization, University of New South Wales Press Ltd, Sydney.
Integrating risk management 
EJIM

17,1

38

Eisenhardt, K.M. and Graebner, M. (2007), "Theory building from cases: opportunities and challenges", Academy of Management Journal, Vol. 50 No. 1, pp. 25-32.

Emblemsvåg, J. and Kjølstad, L.E. (2006), "Qualitative risk analysis: some problems and remedies”, Management Decision, Vol. 44 No. 3, pp. 395-408.

European Federation of Chemical Engineering (1985), Risk Analysis in the Process Industries, Institution of Chemical Engineers Press, London.

Foxon, T.J., Gross, R., Chase, A., Howes, J., Arnall, A. and Anderson, D. (2005), "UK innovation systems for new and renewable energy technologies: drivers, barriers and systems failures”, Energy Policy, Vol. 33 No. 16, pp. 2123-2137.

Gobeli, D.H. and Brown, D.J. (1993), "Improving the process of product innovation”, Research Technology Management, Vol. 36 No. 2, pp. 38-44.

Goffin, K. and Pfeiffer, R. (1999), Innovation Management in UK and German Manufacturing Companies, Anglo-German Foundation for the Study of Industrial Society, London.

Green, M.R. and Serbein, O.N. (1983), Risk Management: Text and Cases, Reston Publishing Company, Virginia, VA.

Griffin, A. (1997), "PDMA research on new product development practices: updating trends and benchmarking best practices", Journal of Product Innovation Management, Vol. 14 No. 6, pp. 429-458.

Halman, J.I.M. and Keizer, A. (1994), "Diagnosing risks in product-innovation projects", International Journal of Project Management, Vol. 12 No. 2, pp. 75-80.

Jantunen, A. (2005), "Knowledge-processing capabilities and innovative performance: an empirical study", European Journal of Innovation Management, Vol. 8 No. 3, pp. 336-349.

Johnson, M.W. (2010), "Risk management and innovation", BusinessWeek.com, 11 September, p. 2.

Keizer, J.A., Halman, J.I.M. and Song, M. (2002), "From experience: applying the risk diagnosing methodology", Journal of Product Innovation Management, Vol. 19 No. 3, pp. 213-232.

Keizer, J.A., Vos, J.P. and Halman, J.I. (2005), "Risks in new product development: devising a reference tool", R\&D Management, Vol. 35 No. 3, pp. 297-309.

Lam, K.C., Wang, D., Lee, P.T.K. and Tsang, Y.T. (2007), "Modelling risk allocation decision in construction contracts", International Journal of Project Management, Vol. 25 No. 5, pp. $485-493$.

Lazzaron, L. (2010), "Vulcan, father of innovation”, EUROPEAN CEO, 1 August, p. 114.

Mahroum, S. (2008), "Innovate out of the economic downturn”, Business Week Online, 28 October, p. 18.

Mu, J., Peng, G. and MacLachlan, D.L. (2009), "Effect of risk management strategy on NPD performance", Technovation, Vol. 29 No. 3, pp. 170-180.

Narvekar, R.S. and Jain, K. (2006), "A new framework to understand the technological innovation process”, Journal of Intellectual Capital, Vol. 7 No. 2, pp. 174-186.

Oke, A. (2007), "Innovation types and innovation management practices in service companies", International Journal of Operations and Production Management, Vol. 27 No. 6, pp. 564-587.

Ozer, M. (2006), "New product development in Asia: an introduction to the special issue", Industrial Marketing Management, Vol. 35 No. 3, pp. 252-261.

Patterson, F.D. and Neailey, K. (2002), “A risk register database system to aid the management of project risk", International Journal of Project Management, Vol. 20 No. 5, pp. 365-374. 
Pyra, J. and Trask, J. (2002), "Risk management post analysis: gauging the success of a simple strategy in a complex project", Project Management Journal, Vol. 33 No. 2, pp. 41-48.

Salomone, T.A. (1995), What Every Engineer Should Know About Concurrent Engineering, Marcel Dekker, New York, NY.

Simon, R. (2009), "New product development and forecasting challenges", Journal of Business Forecasting, Vol. 28 No. 4, pp. 19-21.

Smith, N.J., Merna, T. and Jobling, P. (2006), Managing Risk in Construction Projects, 2nd ed., Blackwell Publishing, Oxford.

Smith, P.G. (1999), "Managing risk as product development schedules shrink", Research Technology Management, Vol. 42 No. 5, pp. 25-32.

Smith, P.G. and Merritt, G.M. (2002), Proactive Risk Management, Productivity Press, New York, NY.

Stevens, G.A. and Burley, J. (1997), “3,000 raw ideas $=1$ commercial success!”, Research Technology Management, Vol. 40 No. 3, pp. 16-27.

Taplin, R. and Schymyck, N. (2005), "An interdisciplinary and cross-cultural approach", in Taplin, R. (Ed.), Risk Management and Innovation in Japan, Britain and the United States, Routledge, London, pp. 1-20.

Tatikonda, M.V. and Rosenthal, S.R. (2000), "Successful execution of product development projects: balancing firmness and flexibility in the innovation process", Journal of Operations Management, Vol. 18 No. 4, pp. 401-425.

Tidd, J., Bessant, J. and Pavitt, K. (2005), Managing Innovation, 3rd ed., Wiley, Sussex.

Turner, J.R. (1993), The Handbook of Project-Based Management, Improving the Process for Achieving Strategic Objective, McGrow-Hill, Berkshire.

van de Ven, A.H., Polley, D.E., Garud, R. and Venkataraman, S. (1999), The Innovation Journey, Oxford University Press, New York, NY.

van Oorschot, K., Sengupta, K., Akkermans, H. and van Wassenhove, L. (2010), "Get fat fast: surviving stage-gate in NPD”, Journal of Product Innovation Management, Vol. 27 No. 6 , pp. 828-839.

Wang, J.T., Lin, W. and Huang, Y.H. (2010), "A performance-oriented risk management framework for innovative R\&D projects”, Technovation, Vol. 30 Nos 11-12, pp. 601-611.

Ward, S.C. (1999), “Assessing and managing important risk”, International Journal of Project Management, Vol. 17 No. 6, pp. 331-336.

Williams, T. (1994), "Using a risk register to integrate risk management in project definition", International Journal of Project Management, Vol. 12 No. 1, pp. 17-22.

Williams, T. (1995), "A classified bibliography of recent research relating to project risk management", European Journal of Operational Research, Vol. 85 No. 1, pp. 18-38.

Worthington, W.J., Collins, J.D. and Hitt, M.A. (2009), "Beyond risk mitigation: enhancing corporate innovation with scenario planning", Business Horizons, Vol. 52 No. 5, pp. $441-450$.

Zhao, J.G. (2005), "Marrying risk register with project trending", AACE International Transactions, Vol. 10 No. 6, pp. 1-6.

\section{About the authors}

John Bowers is a Professor of Management Science at the University of Stirling. His career began in the energy industries before moving to academic life to pursue research in the modelling of complex management systems. He has studied risk in a wide range of industries, from offshore
Integrating risk management

39 
EJIM

17,1

40

oil to healthcare and has published in various journals such as the Journal of the Operational Research Society.

Dr Alireza Khorakian has a BSc in Mechanical Engineering, an MBA and a PhD from the University of Stirling, UK. He is an Assistant Professor in the Department of Management, Faculty of Economic and Administrative Sciences, at the Ferdowsi University of Mashhad (FUM), Iran and has research interests in change management, innovation and technology management, with a particular emphasis on risk and strategic management. Dr Alireza Khorakian is the corresponding author and can be contacted at: a.khorakian@um.ac.ir

To purchase reprints of this article please e-mail: reprints@emeraldinsight.com Or visit our web site for further details: www.emeraldinsight.com/reprints 